$$
\text { Article type : Original Article }
$$

\title{
DEVELOPMENT OF A METHODOLOGY TO CATEGORIZE POULTRY MEAT AFFECTED BY DEEP PECTORAL MYOPATHY
}

Maria Victoria Traffano-Schiffo, ${ }^{1, *}$, Tony Chuquizuta ${ }^{2}$, Marta Castro-Giraldez, Pedro J. Fito $^{3}$

1 Instituto de Química Básica y Aplicada del Nordeste Argentino, IQUIBA-NEA, UNNECONICET, Avenida Libertad 5460, 3400 Corrientes, Argentina.

2 Instituto de Investigación del Mejoramiento Productivo, Universidad Nacional Autónoma de Chota, Jr. 27 de noviembre 768, 06121 Chota, Cajamarca, Perú.

${ }^{3}$ Instituto Universitario de Ingeniería de Alimentos para el Desarrollo, Universitat Politècnica de València, Camino de Vera s/n, 46022 Valencia, Spain.

*Corresponding author: victoriaschiffo@hotmail.com

\section{Abstract}

The growth of poultry production has led to an increase in the incidence of internal defects in chicken and turkey broilers, such as Deep Pectoral Myopathy (DPM). DPM is an ischemic hemorrhage or necrosis caused by the inadequate blood supply of Pectoralis minor and major muscles. Currently, visual appearance is the only parameter used to categorize the damage level. The aim of this research was to develop a scientific methodology to determine the level of damage in poultry breast tenders affected by this myopathy. For this purpose, microstructure, $\mathrm{pH}$, protein

This article has been accepted for publication and undergone full peer review but has not been through the copyediting, typesetting, pagination and proofreading process, which may lead to differences between this version and the Version of Record. Please cite this article as doi: 10.1111/JFPP.15226

This article is protected by copyright. All rights reserved 
and ion content and color were studied. Results allowed identifying three damage levels: normal, hemorrhagic samples with hematomas and blood clots, and necrotic tissues, based on significant variables $(p<0.05)$ measured in Pectoralis minor $\left(\mathrm{pH}, \mathrm{L}^{*}\right.$ and $\left.\mathrm{a}^{*}\right)$, where muscles with myopathy presented $\mathrm{L}^{*}$ values lower than 47 , and necrotic muscles presented $\mathrm{pH}$ values higher than 6.05 .

Keywords: Deep Pectoral Myopathy, chicken meat, poultry quality, DPM categorization, meat quality.

\section{Practical applications}

The appearance of defects in chicken meat is a growing problem due to the intensive genetic selection and the fast growth rate that poultry industry demands. This research provides a scientific methodology, based on biochemical and physicochemical parameters of muscle tissue metabolism, and develops and validates a categorization for deep pectoral myopathy in broilers based on the level of muscle damage. This work, provides an objective and scientific methodology, and coupled with the work published in Traffano-Schiffo et al. (2018) and patented, will allow detecting, identifying and characterizing chickens that have suffered deep pectoral myopathy and the degree of damage.

\section{INTRODUCTION}

In recent years, broiler meat consumption has been drastically increased worldwide, reaching an average of $314.2 \mathrm{~kg} / \mathrm{capita}$ consumed per year (OECD, 2019; Traffano-Schiffo et al., 2018a) and based on OECD-FAO study (2018), it is expected that by 2028 it will continue to be the primary driver of meat market growth, increasing its share of the total production.

Chicken meat growth consumption is mainly due to its nutritional profile, its show a high content of easily absorbed protein, low fat content and polyunsaturated fatty acids (PUFA) (Chmiel et al., 2019, Yalcin et al., 2019). This poultry increase production has been possible by the technological advances implemented in production lines, the strengthening of the sector and mainly due to the strong genetic selection to achieve high growth rate and good carcass yield (Traffano-Schiffo et al., 2018a; Kijowski et al., 2014). Unfortunately, this improvement has led to an increase in the incidence of muscle degenerations due to changes in muscle fibres and vascular structure (Yalcin et al., 2018; Traffano-Schiffo et al., 2017; Hafez, \& Hauck, 2005). 
Deep Pectoral Myopathy (DPM) or commonly known as The Green Muscle Disease (Bilgili, \& Hess, 2008) is produced by different reasons, being common in chickens with hypertrophic musculature, and consists on a breakup of muscle tissue accompanied by internal hemorrhage that can lead necrosis or muscle infarct in their most critical levels (Petracci, \& Cavani, 2012). The main affected muscle is the supracoracoideus or Pectoralis minor. This muscle is very susceptible to this type of injury because it is surrounded by an elastic membrane (fascia) and located between the sternum and the Pectoralis major or Pectoralis superficialis muscle, limiting the expansion during the animal wing beat (Stangierski et al., 2019). Although this disease affects largely to the Pectoralis minor muscles, in some cases the Pectoralis major can also be affected, which suffer degradative changes (Traffano-Schiffo et al., 2018b; Kijowski, \& Konstańczak, 2009).

In latest studies, it has been reported an incidence of DPM of $16.7 \%$ of the total carcasses studied in Italy (Bianchi et al., 2006), 0,06\% in Polonia (Kijowski \& Konstanczak, 2009), 0,51\% in Bulgaria (Dinev \& Kanakov, 2011) and 0,33\% in Iran (Pajohi-alamoti et al., 2016).

Bilgili and Hess (2008) developed an industrial classification, divided in three categories based only on the visual appearance of the Pectoralis muscle. First category presents samples with inflammatory injury in which the deep pectoral muscle shows red coloration, induced by an internal bleeding. The hemorrhages also can be seen in the fibrous surface. It produces an exudation of serous fluid in the damaged area, which gives it a moist and sticky appearance to the lesion. In the second category, the injury to the minor muscle appears well defined, and sometimes surrounded by a hemorrhagic ring. The affected areas are pale pink color and blood clots are observed. In these two categories, after ischemic episode while the animal is still alive, the muscle maintains its capacity to recover the physiological and mechanical activity. In these cases, the muscle necrosis does not appear. The third category is characterized by the presence of muscular necrotic areas, with a progressive degeneration and consequently a greening of muscle tissue produced by the oxidation of blood.

Ischemia can be defined as the lack of blood flow to supply the tissue with oxygen and nutrients and to transport metabolic end products out of the tissue (Schäfer et al., 1998). On the other hand, necrosis can be understood as a cellular death. Cells swell up to the point where the lysis of their plasmic membrane occurs. It can be considered as a cellular explosion which leads to release of the cytoplasmic contents in the surrounding medium which affects other cells by the action of the released intracellular enzymes (Ouali et al., 2006). 
The aim of this research was to develop a scientific methodology based on biochemical and physico-chemical measurements to categorize the damage level in chicken meat affected by DPM, able to be used and easily adapted to meat processing plants.

\section{MATERIALS AND METHODS}

\subsection{Meat samples}

Experiments were performed with 20 males Ross-308 broilers flocks of $42 \mathrm{~d}$ old. Normal and affected by DPM chicken breasts and breast tenders (Pectoralis major and Pectoralis minor) were provided by UVE S.A. slaughterhouse, located in Rafelbunyol, Valencia (Spain) with 5 h postmortem. After slaughter, broilers were bled, defeathered, chilled in a cooling tunnel at $4{ }^{\circ} \mathrm{C}$ for $3 \mathrm{~h}$ and finally deboned.

The trained expert from UVE S.A. industry classified the Pectoralis minors by its visual appearance as normal and according to the damage of the tissue (with hemorrhages, blood clots, and necrosis). Within the damaged tissues, samples were classified in category 1 or hemorrhagic with hematomas and blood clots samples, where the affected areas are well defined, presenting pale pink color, blood clots and sometimes surrounded by a hemorrhagic ring. Category 2 or necrotic samples: samples with green necrotic areas. The classified samples of Pectoralis minor were analyzed with its corresponding Pectoralis major.

\section{2. $\quad$ Experimental Procedure}

Pectoralis minor and major of the same animal were used to carry out the experiment. An amount of 76 samples (Pectoralis major and minor of 76 animals) were analysed: 22 correspond to normal tissues, 27 to category 1 and 27 to category 2 . Samples were transported to the laboratory of the Institute of Food Engineering for Development (IuIAD) at the Polytechnic University of Valencia (UPV) using isothermal bags with ice in order to maintain the samples at $2 \pm 2{ }^{\circ} \mathrm{C}$. Once arrived to the laboratory, the microstructural analyses of damaged and normal samples with $5 \mathrm{~h}$ post-mortem were performed. At $12 \mathrm{~h}$ post-mortem, images of the samples were taken in order to perform the image analyses. Moreover, the $\mathrm{pH}$, protein content, colour and ion content were measured at three locations and averaged. All determinations were performed in pectoralis minor and major of the different categories. 
The $\mathrm{pH}$ of the samples was obtained using a punch $\mathrm{pH}$-meter (S-20 SevenEasy ${ }^{\mathrm{TM}}$, Mettler Toledo, Barcelona, Spain). These measurements were performed on the ventral side of the pectoralis minor and on the dorsal side of the pectoralis major, also corresponding with the most affected area by DPM disease. The color was measured using a colorimeter Minolta CM-3600D, with 8$\mathrm{mm}$ aperture and calibrated with a white plate (Minolta Co. Ltd., Tokio, Japan). Three measurements were performed for each sample. The instrument measures reflectance spectrum between 400 and $700 \mathrm{~nm}$ at $10 \mathrm{~nm}$ intervals. Color coordinates CIE L*a*b* were instrumentally calculated based on D65 illuminant and $10^{\circ}$ observer (CIE, 1978).

Myosin, collagen and sarcoplasmic and actin proteins content were obtained from the transition energies and the latent heat of denaturation of the proteins following the method proposed by Traffano-Schiffo et al. (2021, 2018b). Briefly, Proteins phase transitions were calculated using a differential scanning calorimeter Mettler Toledo DSC 1 (Mettler Toledo, Barcelona, Spain) and using around 20-30 mg of sample enclosed in hermetically sealed aluminium pans (Mettler Toledo, ME-00026763). Meat samples were heated from 15 to $115{ }^{\circ} \mathrm{C}$ at a heating rate of 10 ${ }^{\circ} \mathrm{C} / \mathrm{min}$ under $\mathrm{N}_{2}$ (flowed at $200 \mathrm{~min} / \mathrm{mL}$ ).

Microstructure was analyzed in the affected areas, using a Cryo-SEM, using a Cryostage CT1500C unit (Oxford Instruments, Witney, UK), coupled to a Jeol JSM-5410 scanning electron microscope (Jeol, Tokyo, Japan) (Traffano-Schiffo et al., 2018b).

Ion quantification $\left(\mathrm{Li}^{+}, \mathrm{Na}^{+}, \mathrm{Ca}^{2+}, \mathrm{NH}_{4}^{+}, \mathrm{K}^{+}\right.$and $\mathrm{Mg}^{2+}$ ) was carried out using an ion exchange chromatograph (Methrom Ion Analysis, Herisau, Switzerland), coupled to a universal standard column (Metrosep C2-150, $4.0 \times 150 \mathrm{~mm}$ ), following the procedure described in a previous work (Traffano-Schiffo et al., 2018b).

\subsection{Image Analysis}

Image analysis was performed obtaining the images of the ventral side of normal and damaged Pectoralis minor chicken meat by a digital camera Canon EOS 550D, with a size of $2592 \times 1728$ pixels and a resolution of $16 \mathrm{pixel} / \mathrm{mm}$. The images were taken placing the samples inside an inspection black chamber, which minimize the background light, and where the camera and the lighting system were placed. For a correct illumination three fluorescent tubes (PHILIPS TLD18W/965, $60 \mathrm{~cm}$ in length) were used in order to obtain the appropriate lighting condition (illuminant D65), with a color temperature of $6500 \mathrm{~K}$. Finally, the camera lens was installed on the top, focusing the sample with $10^{\circ}$ slope. 
In order to calibrate the digital color system, the color values of 24 color charts (CLASSIC X-rite, USA) with a known CIE L*a*b* (CIE, 1978) coordinates were measured and compared with the parameters provided by the manufacturer. The average CIE $\mathrm{L}^{*} \mathrm{a} * \mathrm{~b}$ coordinates of the muscle ventral side was obtained and the damaged areas. The analysis of damaged areas (blood clots, hemorrhagic and necrotic areas) was performed by Adobe ${ }^{\circledR}$ Photoshop ${ }^{\circledR}$ CS6 software (Adobe Systems Inc., San Jose, CA, USA).

\subsection{Statistical analysis}

Statistical analysis was carried out with the Statgraphics Centurion XVI Software (Statgraphics, Warrenton, VA, USA). One-Way ANOVA analyses were performed to determine statistically significant differences with $95 \%$ of confidence $(p<0.05)$. Limits of decision tree and significant variables were obtained by multiple linear regressions with an ANOVA analysis $(p<0.05)$. The data shown in Tables 1 and 2 represent the means and the standard errors means (SEM).

\section{RESULTS AND DISCUSSION}

Figure 1 shows the microstructural study of normal and necrotic tissue of breast and breast tender at $5 \mathrm{~h}$ of postmortem time (pmt). After an ischemic episode, the muscle tissue can recover its structure if the blood flow is restored in an interval of $15-20$ minutes and if there was not suffered any structural lesion (Martín-García, 2009). Above this time, all the glycogen has been consumed; appearing major structural alterations (see Figure 1): myofibrils suffer an excessive elongation and the sarcolemma develops separation areas. Some studies reported that after the infarct, collagen content is reduced significantly (Takahashi, Barry, \& Factor, 1990). Also, the presence of lesions in the cell membrane is evident.

In Figure 1a and 1b, micrographies of normal chicken breast tender and breast respectively, after 5 hours of post-mortem time are shown, where it is possible to appreciate the correct packaging of the fibrillar cells. Cells are formed by the structural proteins, myosin and actin, which are responsible of the muscular contraction and relaxation. Moreover, they are packaged by the collagen protein, which confers capacity to maintain the tension. However, in Figure 1c and 1d, it is possible to observe micrographies of muscle tissue after an infarct episode, where the strong myopathy shows a high level of collagen degradation (endomysium). This degradation is induced by the accumulation of electrolytes in this area, generating strong repulsions between the adjacent 
collagen covers (Schmidt, Carciofi, Laurindo, \& 2008), and a high degradation level of structural proteins (actin and myosin).

Figure 2 shows three samples of Pectoralis minor with different DPM damages. Figure 2a shows a normal sample (normal tissue), $2 \mathrm{~b}$ hemorrhagic sample with hematomas and a blood clots, and $2 \mathrm{c}$ a necrotic sample. Moreover, Figure $2 \mathrm{~d}$ shows a micrograph of hemorrhagic tissue, where it is possible to observe the presence of blood clots (detailed by arrows) and the muscular breakdown. However, Figure 2e shows a micrograph of a necrotic Pectoralis minor, where the loss of the cellular structure and the endomysial inflammation can be appreciated (indicated by arrows).

Table 1 shows the electrolytes content of normal and DPM muscles where the ischemic effect is observed slightly in the increase of calcium (Miyoshi et al., 1992). Muscle rupture processes reach the breakdown of some organs such as mitochondria, $\mathrm{K}^{+}{ }_{\text {ATP }}$ channels stores in the mitochondrial intermediate space a high concentration of potassium ions, which, when broken, increase the concentration of free potassium ions (Horimoto et al., 2000; Gürke et al., 2000). The same happens with other ions as sodium, which are found in other organelles where the $\mathrm{Na}^{+}{ }_{\mathrm{ATP}}$ channels stores high quantity of sodium ions (Immke, \& McCleskey, 2001) and induced by the lactic generation, which are release to the muscle. In degenerative processes with loss of blood supply, $\mathrm{pH}$ decreases after the ischemic phenomenon (lactic and phosphate formation). And time after the ischemic phenomenon the $\mathrm{pH}$ is equilibrated, increasing again, favoring the formation of salts from the cationic and anionic species causing a decrease of free ions (Zweier et al., 1995). Therefore, the hemorrhagic category presents high levels of potassium and sodium ions, which are reduced if the system becomes infarcted and necrotic tissue (Horimoto et al., 2000). However, no significant differences among the $\mathrm{Mg}^{+2}$ were found. The $\mathrm{K}^{+}$ATP channels imbalance effect and lactate and phosphate production cause a change in the electric disequilibrium inside the muscle tissue. This causes an imbalance in the protein transmembrane transports $\left(\mathrm{Ca}^{2+}\right.$ protein channel and $\mathrm{Na}^{+} / \mathrm{K}^{+}$protein channel) inducing a release of calcium and sodium ions to the medium.

Figure 3 shows the structural proteins degradation estimated by DSC. Ageing process and myopathies produce degradation in the structural proteins, and it is possible to determine the effect of the myopathy comparing normal with damaged tissue at the same post-mortem time. Figure 3 shows the mass fraction of each structural protein (myosin, actin, collagen and sarcoplasmic 
proteins) in normal (code samples 0), hemorrhagic with hematomas and/or blood clots samples (code samples 1), and necrotic samples (code samples 2), where it is possible to observe how the quantity of myosin decreases in Pectoralis minor depending on the level of damage (Fig. 3a). On the other hand, necrotic samples show a higher decrease of the collagen and sarcoplasmic proteins contents comparing with normal tissue in Pectoralis minor (Fig. 3b). This result can be related with the high level of degradation in the collagen observed in the micrographies showed in Figure 1c and 1d. Also, similar results were obtained in the research developed in 1990 by Takahashi et al. With regard to Pectoralis major, a significant decrease in myosin content is appreciated in necrotic tissue comparing with the others two categories (Fig. 3d). Collagen and sarcoplasmic proteins also show a significant decrease comparing to hemorrhagic samples (Fig. 3e). Finally, actin degradation of damaged categories is significant higher with regard to the normal samples both in Pectoralis minor and in major (Fig. 3c and f).

The process of necrosis is progressive and the damage produced in muscle tissue is not uniform. An image analysis was performed in order to estimate the damaged areas (blood clots, hemorrhagic and necrotic areas) by category. The criterion used to select the damages in the muscle can be observed in Figure 4 and the results obtained are shown in Tables 2 and 3. Table 2 shows the distribution of hemorrhagic areas, blood clots and necrotic, where it is possible to observe how category 1 does not present necrotic areas but accumulates large hemorrhagic areas. However, category 2 shows large necrotic areas with very few hemorrhages, not showing significant differences in the presence of blood clots between the two categories.

Table 3 shows the percentage of samples with low incidence (less than $30 \%$ of affected area), medium incidence (between 30 and $60 \%$ of affected area) and high incidence (more than $60 \%$ of affected area), for the three incidences mentioned above, hemorrhagic area, coagulated area and necrotic area.

In Table 3 it is possible to observe how category 1 shows a low incidence of samples with blood clots while category 2 incidence reaches more than $50 \%$ of samples. In addition, category 1 shows a homogeneous distribution of the incidence of hemorrhagic areas, the majority being in a medium incidence, however, in category 2 the hemorrhagic areas have a slight incidence. Finally, in Table 3 , it can be observed that category 2 presents half of the necrotic samples with slight incidence. 
Figure 5 shows the $\mathrm{L}^{*}, \mathrm{a}^{*}, \mathrm{~b}^{*}$ coordinates and the $\Delta \mathrm{E}^{*}$ obtained for the three categories studied. The least significance difference (LSD) intervals ( $95 \%$ confidence) are also shown. In the CIE L* $a^{*} b^{*}$ space, $L^{*}$ coordinate represents lightness, where $L^{*}=0$ is completely black, and $L^{*}=100$ is completely white, $a^{*}$ represents the red-green color and $b^{*}$ the yellow-blue color of the sample. Significant differences $(p<0.05)$ in $\mathrm{L}^{*}$ coordinate between normal and damaged samples can be observed. Samples with damaged tissue by DPM show a decrease in the L* coordinate (Fig. 5a). Hemorrhagic samples with hematomas and blood clots show significant $(p<0.05)$ higher a* values (redder color) (Fig. 5b) than normal and necrotic samples, as a consequence of the blood clots formation. On the other hand, $b^{*}$ coordinate (Fig. 5c) is higher in normal samples than in DPM samples, showing a higher yellow color in normal samples. $\Delta \mathrm{E}^{*}$ parameter show that the color differences among normal samples and DPM samples are significant.

Figure 6 shows the average reflectance spectra for damaged and normal tissues. Hemorrhages are considered as a release of blood into the tissues and follow the hemoglobin metabolism, where the hemoglobin is degraded to biliverdin, carbon monoxide and free iron due to an oxidative reaction catalyzed by heme oxygenase. This oxidation involves the consumption of three molecules of $\mathrm{O}_{2}$ (Fondevila, Busuttil, \& Kupiec-Weglinski, 2003). It is known that this metabolism is related with bruises formations in muscle tissues (Jeney et al., 2013; Biswas, Singh, \& Sharma, 2012; Hughes et al., 2004) and it also explains the green color of the necrotic tissues (Brooks, 2016; Hill, \& Miller, 2013). In this context, a colorimetric analysis of the muscle tissue according to the deep pectoral myopathy category can let to understand the involved metabolites in the muscle damage. Lindahl (2005) identified different peaks in the reflectance spectrum at 473, 572 and $610 \mathrm{~nm}$, which correspond to myoglobin, metamyoglobin and oxymyoglobin, respectively. On the other hand, Thavarajah et al. (2012) identified a peak at $530 \mathrm{~nm}$ for biliverdin. In figure 6 it is possible to observe that the hemorrhagic samples with hematomas and blood clots present higher reflectance values in the range from $600 \mathrm{~nm}$ to $700 \mathrm{~nm}$ which can be related with the higher hemoglobin content of this category. In contrast, category 2 or necrotic samples showed a peak near $530 \mathrm{~nm}$, which can be related with the higher biliverdin content of this category. Finally, normal samples present similar reflectance values along the spectra, resulting in the normal color of raw chicken breast.

Figure 7 shows that the $\mathrm{pH}$ (at $12 \mathrm{~h}$ post-mortem) of Pectoralis minor allow us to discriminate the normal tissues from hemorrhagic samples with hematomas and blood clots and necrotic samples. 
Also, it can be observed that the damaged tissues present higher $\mathrm{pH}$ values than the normal tissue. In the same figure, the $\mathrm{pH}$ of Pectoralis major is shown, but in this case, there were no significant $(p<0.05)$ differences among categories.

As it was explained in the introduction section, there exists an industrial categorization of DPM. This categorization consists in an inaccurate and unquantifiable parameter (visual), so it is necessary to categorize the damage in poultry objectively. For this purpose, the authors propose a classification based on significant $(p<0.05)$ variables, measured in Pectoralis minor $\left(\mathrm{pH}, \mathrm{L}^{*}\right.$ and $\mathrm{a}^{*}$ coordinates) (Table 4$)$.

In order to demonstrate the reliability of the classification proposed by the authors, a multifactorial algorithm using the parameters shown in Table 4 was developed. Figure 8 shows the predicted categories based on the algorithm proposed by the authors with regard to the industrial trained expert categorization, where it is possible to observe the effectiveness of the previously classification proposed.

\section{CONCLUSIONS}

By means of a microstructural and physicochemical analysis of Pectoralis minor and major, which include the analysis of cations, proteins, $\mathrm{pH}$, microstructural changes, or color variations by areas, it has been possible to describe the transformations that occur during an ischemia with a hemorrhagic or necrotic process, namely an angina or an infarct disease.

The categorization by industrial experts has been compared with the categorization by image analysis in proportion of hemorrhagic tissue, with clots and necrotic, observing a greater appearance of tissue with clots in the breast tenders categorized as category 2 or necrotic than in category 1. Moreover, it has been observed the appearance of hemorrhagic areas in both categories and the null appearance of necrotic area in category 1.

Finally, it has been developed an objective and scientific methodology to categorize the level of the DPM in poultry. This categorization is able to differentiate three categories: normal, hemorrhagic samples (angina) and necrotic samples (infarct).

\section{ACKNOWLEDGMENTS}

This article is protected by copyright. All rights reserved 
The authors acknowledge the financial support from: the Spanish Ministerio de Economía, Industria y Competitividad, Programa Estatal de $\mathrm{I}+\mathrm{D}+\mathrm{i}$ orientada a los Retos de la Sociedad AGL2016-80643-R, Agencia Estatal de Investigación (AEI) and Fondo Europeo de Desarrollo Regional (FEDER).

The authors would like to thanks the Electronic Microscopy Service of the Universitat Politècnica de València for its assistance in the use of Cryo-SEM.

\section{CONFLICT OF INTEREST}

Authors have declared no conflicts of interest for this article.

\section{REFERENCES}

Bianchi, M., Petracci, M., Franchini, A., \& Cavani, C. (2006). The occurrence of deep pectoral myopathy in roaster chickens. Poultry Science, 85(10), 1843-1846.

Bilgili, S. F., \& Hess, J. (2008). Green muscle disease. Reducing the incidence in broiler flock. Ross Tech, 8(48), 3.

Biswas, G., Singh, V. P., \& Sharma, J. (2012). Ageing of Bruise: Review of Histo-Chemical Changes with Time. Indian Internet Journal of Forensic Medicine \& Toxicology, 10(1), 15-17.

Brooks, J. W. (2016). Postmortem changes in animal carcasses and estimation of the postmortem interval. Veterinary Pathology, 53(5), 929-940.

Chmiel, M., Roszko, M., Adamczak, L., Florowski, T., \& Pietrzak, D. (2019). Influence of storage and packaging method on chicken breast meat chemical composition and fat oxidation. Poultry Science, 98(6), 2679-2690.

CIE. 1978. International Commission on Illumination, recommendations on uniform color spaces, color, difference equations, psychometric color terms. CIE publication No. 15. Paris, France: Bureau Central de la CIE.

Dinev, I., \& Kanakov, D. (2011). Deep pectoral myopathy: prevalence in 7 weeks old broiler chickens in Bulgaria. Revue de Médecine Vétérinaire, 162(6), 279-283. Pajohi-alamoti, M., Khaledian, S., \& Mohammadi, M. (2016). Study of green muscle disease in some condemned broiler chicken from Iran. Comparative Clinical Pathology, 25, 1193-1196.

Fondevila, C., Busuttil, R. W., \& Kupiec-Weglinski, J. W. (2003). Hepatic ischemia/reperfusion injury-a fresh look. Experimental and Molecular Pathology, 74(2), 86-93. 
Gürke, L., Mattei, A., Chaloupka, K., Marx, A., Sutter, P. M., Stierli, P., ... \& Heberer, M. (2000). Mechanisms of ischemic preconditioning in skeletal muscle. Journal of Surgical Research, 94(1), $18-27$.

Hafez, H. M., \& Hauck, R. (2005). Genetic selection in turkeys and broilers and their impact on health conditions. In World Poultry Science Association, 4th European Poultry Genetics Symposium, Dubrovnik, Croatia (pp. 6-8).

Hill, A. G., \& Miller, R. (2013). Exercise-induced deep pectoral necrosis in white-headed pigeons (Columba leucomela). Journal of Zoo and Wildlife Medicine, 44(4), 990-995.

Horimoto, H., Gaudette, G. R., Saltman, A. E., \& Krukenkamp, I. B. (2000). The role of nitric oxide, $\mathrm{K}+\mathrm{ATP}$ channels, and cGMP in the preconditioning response of the rabbit. Journal of Surgical Research, 92(1), 56-63.

Hughes, V. K., Ellis, P. S., Burt, T., \& Langlois, N. E. I. (2004). The practical application of reflectance spectrophotometry for the demonstration of haemoglobin and its degradation in bruises. Journal of Clinical Pathology, 57(4), 355-359.

Immke, D. C., \& McCleskey, E. W. (2001). Lactate enhances the acid-sensing $\mathrm{Na}+$ channel on ischemia-sensing neurons. Nature Neuroscience, 4(9), 869-870.

Jeney, V., Eaton, J. W., Balla, G., \& Balla, J. (2013). Natural history of the bruise: formation, elimination, and biological effects of oxidized hemoglobin. Oxidative Medicine and Cellular Longevity, 2013.

Kijowski, J., \& Konstańczak, M. (2009). Deep pectoral myopathy in broiler chickens. Bull. Vet. Inst. Pulawy, 53, 487-491.

Kijowski, J., Kupińska, E., Stangierski, J., Tomaszewska-Gras, J., \& Szablewski, T. (2014). Paradigm of deep pectoral myopathy in broiler chickens. World's Poultry Science Journal, 70(1), $125-138$.

Lindahl, G. (2005). Colour characteristics of fresh pork. PhD Diss. Swedish Univ. of Agricultural Sciences, Uppsala.

Martín-García, A. (2009). Estudio de marcadores bioquímicos de interés en el diagnóstico y pronóstico del síndrome coronario agudo. PhD Diss. Univ. Complutense de Madrid, Madrid.

Miyoshi, Y., Nakaya, Y., Wakatsuki, T., Nakaya, S., Fujino, K., Saito, K., \& Inoue, I. (1992). Endothelin blocks ATP-sensitive $\mathrm{K}+$ channels and depolarizes smooth muscle cells of porcine coronary artery. Circulation Research, 70(3), 612-616.

OECD, (2019). Meat consumption (indicator). https://doi.org/10.1787/fa290fd0-en. 
OECD-FAO, (2019). AGRICULTURAL OUTLOOK 2019-2028. OECD/FAO 2019. http://www.fao.org/3/i9166e/i9166e_Chapter6_Meat.pdf

Ouali, A., Herrera-Mendez, C. H., Coulis, G., Becila, S., Boudjellal, A., Aubry, L., \& Sentandreu, M. A. (2006). Revisiting the conversion of muscle into meat and the underlying mechanisms. Meat Science, 74(1), 44-58.

Petracci, M., \& Cavani, C. (2012). Muscle growth and poultry meat quality issues. Nutrients, 4(1), $1-12$.

Schäfer, M., Schlegel, C., Kirlum, H. J., Gersing, E., \& Gebhard, M. M. (1998). Monitoring of damage to skeletal muscle tissues caused by ischemia.Bioelectrochemistry and Bioenergetics, 45(2), 151-155.

Schmidt, F. C., Carciofi, B. A. M., \& Laurindo, J. B. (2008). Salting operational diagrams for chicken breast cuts: hydration-dehydration. Journal of Food Engineering, 88(1), 36-44.

Stangierski, J., Tomaszewska-Gras, J., Baranowska, H. M., Krzywdzińska-Bartkowiak, M., \& Konieczny, P. (2019). The effect of deep pectoral myopathy on the properties of broiler chicken muscles characterised by selected instrumental techniques. European Food Research and Technology, 245(2), 459-467.

Takahashi, S., Barry, A. C., \& Factor, S. M. (1990). Collagen degradation in ischaemic rat hearts. Biochemical Journal, 265(1), 233-241.

Thavarajah, D., Vanezis, P., \& Perrett, D. (2012). Assessment of bruise age on dark-skinned individuals using tristimulus colorimetry. Medicine, Science and the Law, 52(1), 6-11.

Traffano-Schiffo, M. V., Castro-Giraldez, M., Colom, R. J., \& Fito, P. J. (2017). Development of a spectrophotometric system to detect white striping physiopathy in whole chicken carcasses. Sensors, 17(5), 1024.

Traffano-Schiffo, M. V., Castro-Giraldez, M., Colom, R. J., \& Fito, P. J. (2018a). Innovative photonic system in radiofrequency and microwave range to determine chicken meat quality. Journal of Food Engineering, 239, 1-7.

Traffano-Schiffo, M. V., Castro-Giraldez, M., Colom, R. J., Talens, P., \& Fito, P. J. (2021). New methodology to analyze the dielectric properties in radiofrequency and microwave ranges in chicken meat during postmortem time. Journal of Food Engineering, 110350.

Traffano-Schiffo, M. V., Castro-Giraldez, M., Herrero, V., Colom, R. J., \& Fito, P. J. (2018b). Development of a non-destructive detection system of Deep Pectoral Myopathy in poultry by dielectric spectroscopy. Journal of Food Engineering, 237, 137-145. 
Yalcin, S., Ozkan, S., Acar, M. C., \& Meral, O. (2018). The occurrence of deep pectoral myopathy in broilers and associated changes in breast meat quality. British Poultry Science, 59(1), 55-62.

Yalcin, S., Şahin, K., Tuzcu, M., Bilgen, G., Özkan, S., Izzetoğlu, G. T., \& Işik, R. (2019). Muscle structure and gene expression in pectoralis major muscle in response to deep pectoral myopathy induction in fast-and slow-growing commercial broilers. British Poultry Science, 60(3), 195-201.

Zweier, J. L., Wang, P., Samouilov, A., \& Kuppusamy, P. (1995). Enzyme-independent formation of nitric oxide in biological tissues. Nature medicine, 1(8), 804-809. 
Table 1. Electrolytes content (ppm) of normal (non-damaged), category 1 or hemorrhagic samples with hematomas and blood clots, and category 2 or necrotic samples.

\begin{tabular}{|c|ccc|ccc|ccc|}
\cline { 2 - 9 } \multicolumn{1}{c|}{} & \multicolumn{2}{c|}{$\begin{array}{c}\text { NORMAL } \\
(\mathrm{n}=22)\end{array}$} & \multicolumn{2}{|c|}{$\begin{array}{c}\text { Category } 1 \\
(\mathrm{n}=27)\end{array}$} & \multicolumn{2}{|c|}{$\begin{array}{c}\text { Category 2 } \\
(\mathrm{n}=27)\end{array}$} \\
\hline $\mathrm{Na}^{+}$ & 130 & \pm & 8 & 1580 & \pm & 28 & 868 & \pm & 63 \\
\hline $\mathrm{K}^{+}$ & 353 & \pm & 27 & 1646 & \pm & 86 & 556 & \pm & 81 \\
\hline $\mathrm{Ca}^{2+}$ & 190 & \pm & 43 & 342 & \pm & 69 & 213 & \pm & 69 \\
\hline $\mathrm{Mg}^{2+}$ & 80 & \pm & 12 & 78 & \pm & 6 & 87 & \pm & 12 \\
\hline
\end{tabular}


Table 2. Hemorrhagic, hematoma/blood clots (category 1) and necrotic (category 2) areas of DPM breast tenders.

\begin{tabular}{|c|c|c|}
\cline { 2 - 3 } \multicolumn{1}{c|}{} & \multicolumn{2}{|c|}{$\begin{array}{c}\text { Average area per category } \\
(\%)\end{array}$} \\
\cline { 2 - 3 } & $\begin{array}{c}\text { Category } 1 \\
(\mathrm{n}=27)\end{array}$ & $\begin{array}{c}\text { Category } 2 \\
(\mathrm{n}=27)\end{array}$ \\
\hline Hemorrhagic & $41 \pm 17$ & $9 \pm 8$ \\
\hline Blood clots & $5 \pm 3$ & $3 \pm 3$ \\
\hline Necrotic & $0 \pm 0$ & $31 \pm 22$ \\
\hline
\end{tabular}


Table 3. Percentage of samples with low incidence (less than $30 \%$ of affected area), medium incidence (between 30 and $60 \%$ of affected area) and high incidence (more than $60 \%$ of affected area) of category 1 or muscles with hemorrhagic and hematoma/blood clots and category 2 or necrotic breast tenders.

\begin{tabular}{|c|c|c|c|}
\cline { 3 - 4 } \multicolumn{2}{c|}{} & \multicolumn{2}{c|}{ Percentage of samples } \\
\cline { 3 - 4 } \multicolumn{2}{c|}{} & Category 1 & Category 2 \\
\hline \multirow{3}{*}{ Hemorrhagic area } & $1-30 \%$ & 24 & 84.6 \\
\cline { 2 - 4 } & $30-60 \%$ & 60 & 0 \\
\cline { 2 - 4 } & $60-100 \%$ & 16 & 0 \\
\hline \multirow{3}{*}{ Blood clots } & $1-30 \%$ & 16 & 53.8 \\
\cline { 2 - 4 } & $30-60 \%$ & 4 & 7.7 \\
\cline { 2 - 4 } & $60-100 \%$ & 0 & 0 \\
\hline \multirow{5}{*}{ Necrotic } & $1-30 \%$ & 0 & 53.8 \\
\cline { 2 - 4 } & $30-60 \%$ & 0 & 23.1 \\
\cline { 2 - 4 } & $60-100 \%$ & 0 & 23.1 \\
\hline
\end{tabular}


Table 4. Categorization of the Pectoralis minor muscle according to the deep pectoral myopathy. Normal (non-damaged), category 1 or hemorrhagic samples with hematomas and blood clots, and category 2 or necrotic samples.

\begin{tabular}{|c|c|c|c|}
\hline & Normal & Category 1 & Category 2 \\
\hline $\mathbf{L}^{*}$ & $>53$ & $<47$ & $<47$ \\
\hline $\mathbf{a}^{*}$ & $<1.33$ & $>1.53$ & $<1.13$ \\
\hline $\mathbf{p H}$ & $<6.05$ & $<6.05$ & $>6.5$ \\
\hline
\end{tabular}




\section{Figure Captions}

FIGURE 1. a) normal Pectoralis minor with 5 hpm 500x; b) normal Pectoralis major with 5 hpm 500x; c) necrotic Pectoralis minor with 5 hpm 500x; and d) necrotic Pectoralis major with 5 hpm 1000x.

FIGURE 2. Pectoralis minor, where: a) normal tissue, b) hemorrhagic sample with hematomas and blood clots, c) necrotic, d) Micrograph (1500x) of hemorrhagic tissue, and e) Micrograph (500x) of necrotic sample.

FIGURE 3. Mass fraction of myosin $\left(\mathrm{g}_{\text {protein }} / \mathrm{g}_{\text {Total }}\right)$, collagen and sarcoplasmic proteins, and actin of Pectoralis minor and major, where: 0 corresponds to normal tissues, 1 to hemorrhagic samples with hematomas and blood clots, and 2 to necrotic samples. Different letters in the same graphic $(\mathrm{a}-\mathrm{b})$ indicate significant differences $(p<0.05)$.

FIGURE 4. Schematic representation of the area selection according to the DPM damage in Pectoralis minor.

FIGURE 5. CIELab coordinates of Pectoralis minor, where: (a) $L^{*}$, (b) $a^{*}$, (c) $b^{*}$ and (d) $\Delta \mathrm{E}^{*}$ color variation, where: 0 normal tissues, 1 hemorrhagic samples with hematomas and blood clots, and 2 necrotic samples. Different letters on the categories (a-b) indicate significant differences $(p<0.05)$.

FIGURE 6. Average reflectance spectra of Pectoralis minor for the normal tissue (black color), category 1 tissue (blue color) and category 2 tissue (green color).

FIGURE 7. a) $\mathrm{pH}$ of the Pectoralis minor at $12 \mathrm{~h}$ post-mortem, b) $\mathrm{pH}$ of the Pectoralis major, where: 0 normal tissues, 1 hemorrhagic samples with hematomas and blood clots and 2 necrotic samples. Different letters (a-c) indicate significant differences $(p<0.05)$.

FIGURE 8. Predicted categories based on the developed algorithm versus the industrial categories. 

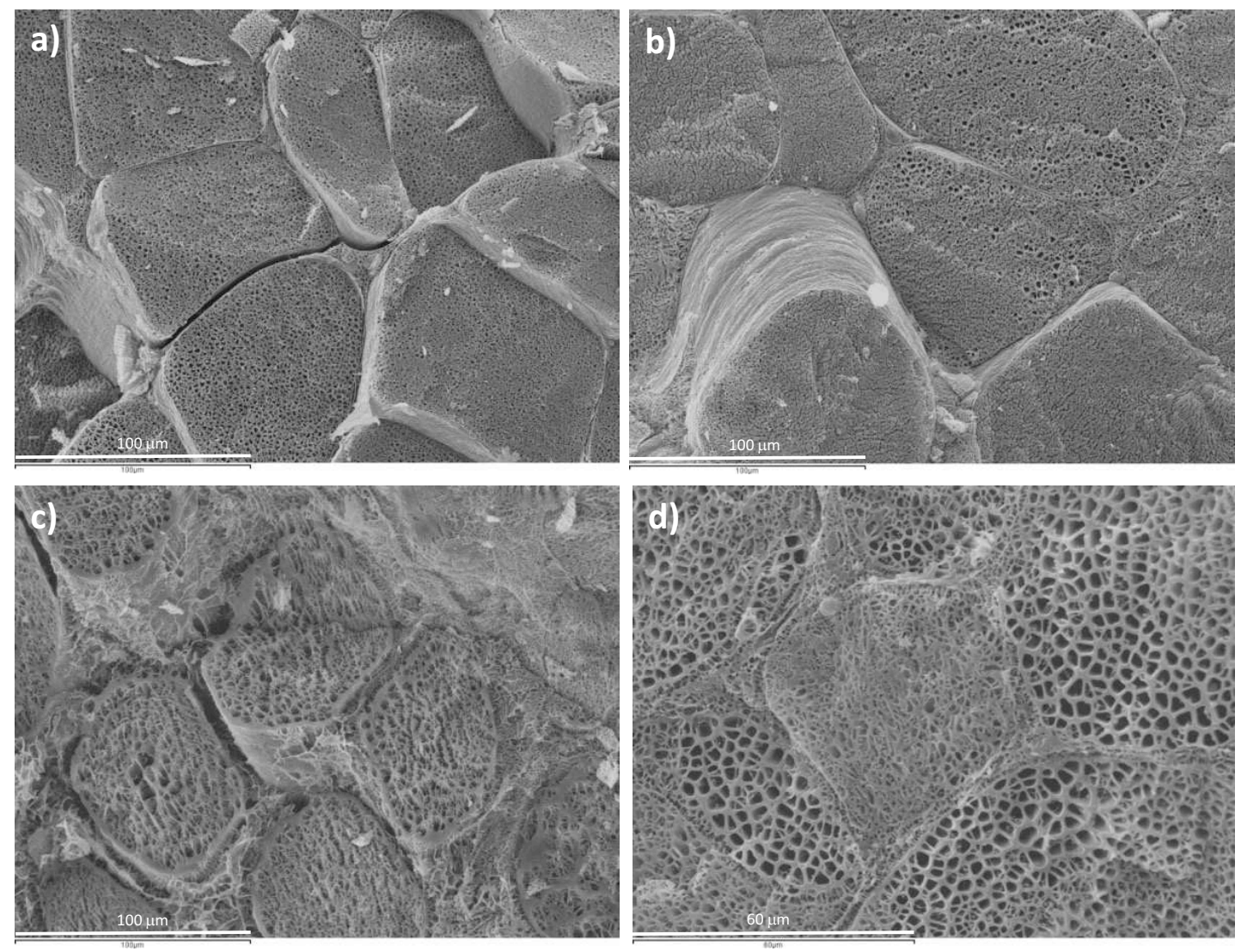

Figure 1.

This article is protected by copyright. All rights reserved 


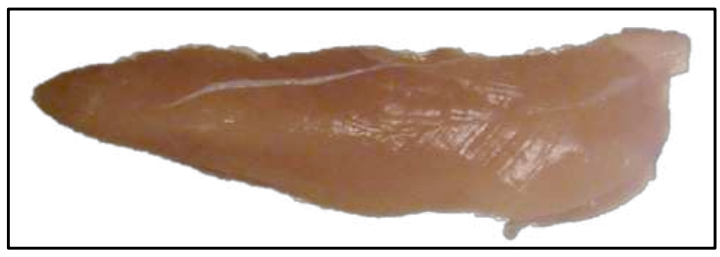

a)

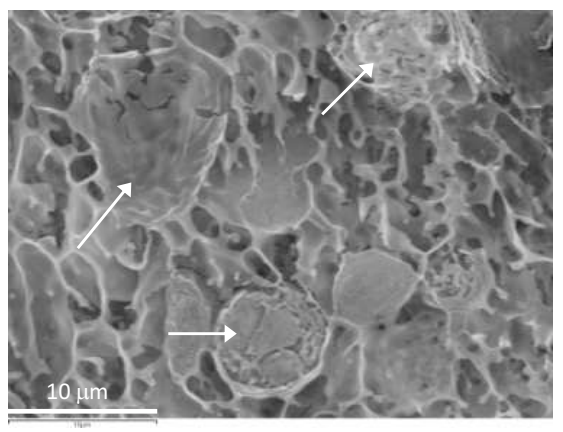

d)

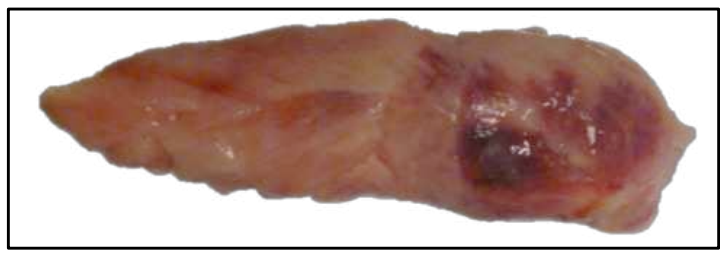

b)

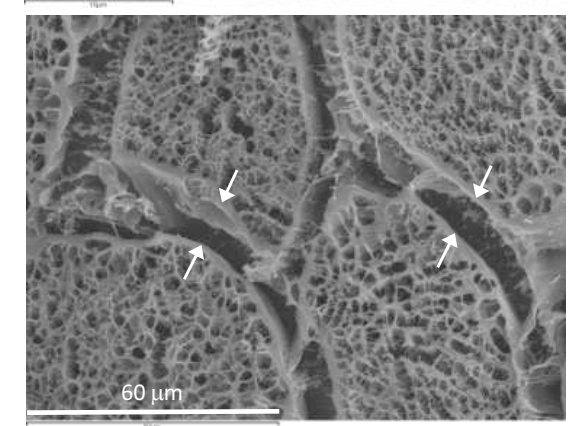

e)

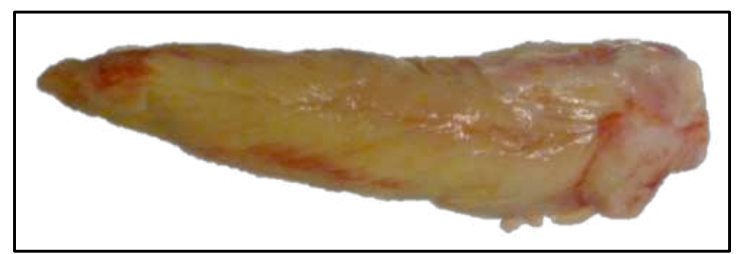

c)

Figure 2.

This article is protected by copyright. All rights reserved 

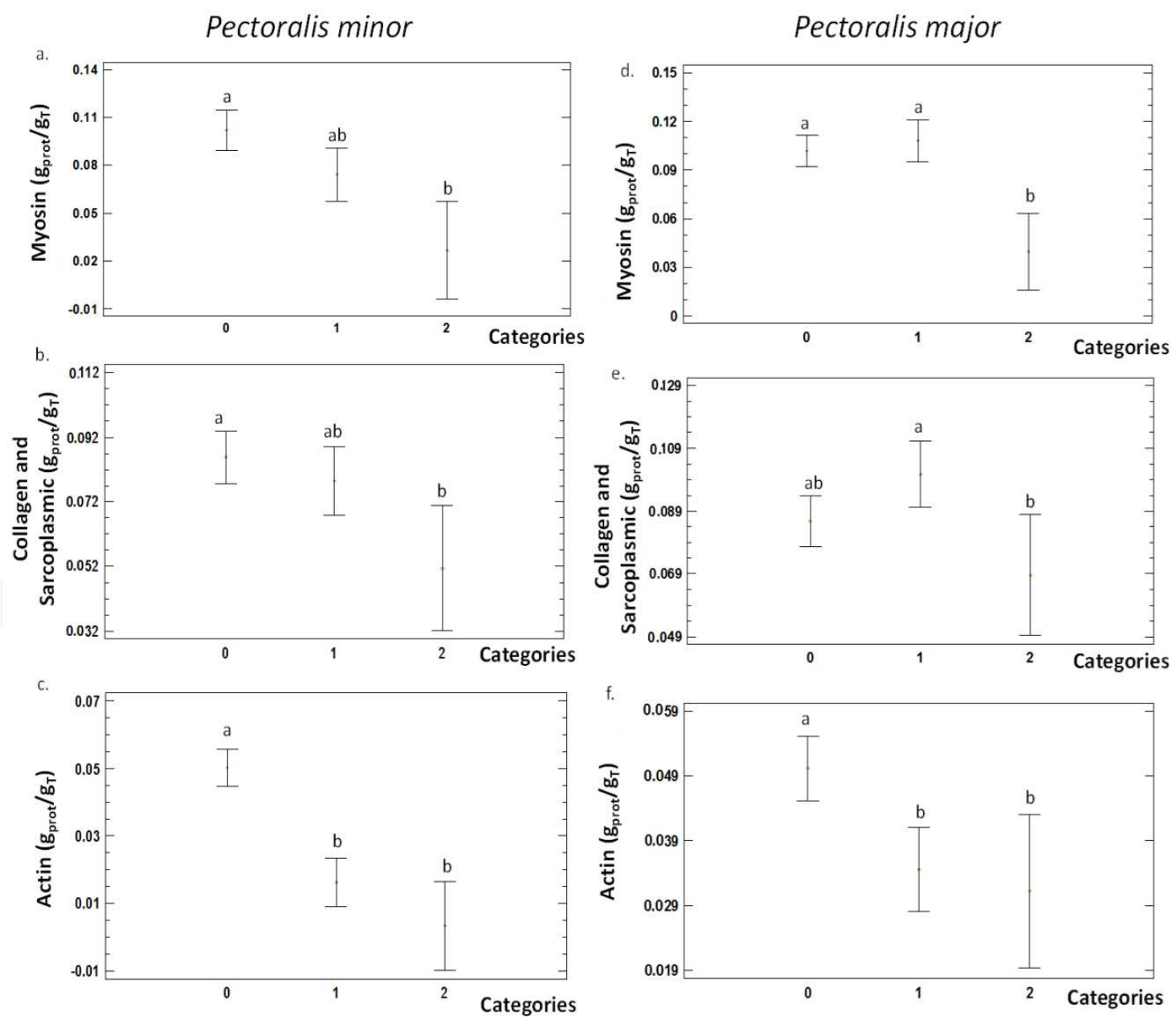

Figure 3. 


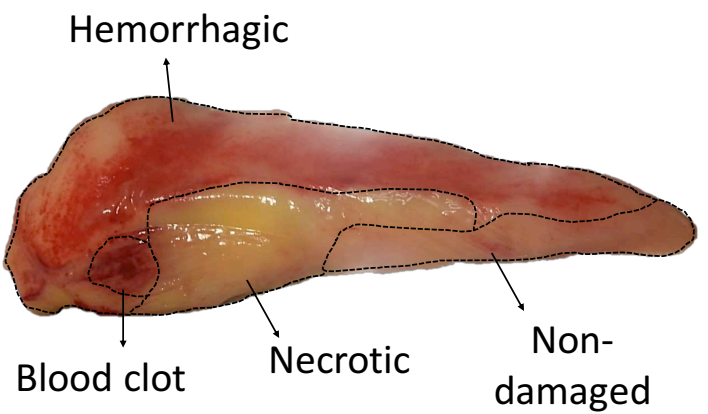

Figure 4. 

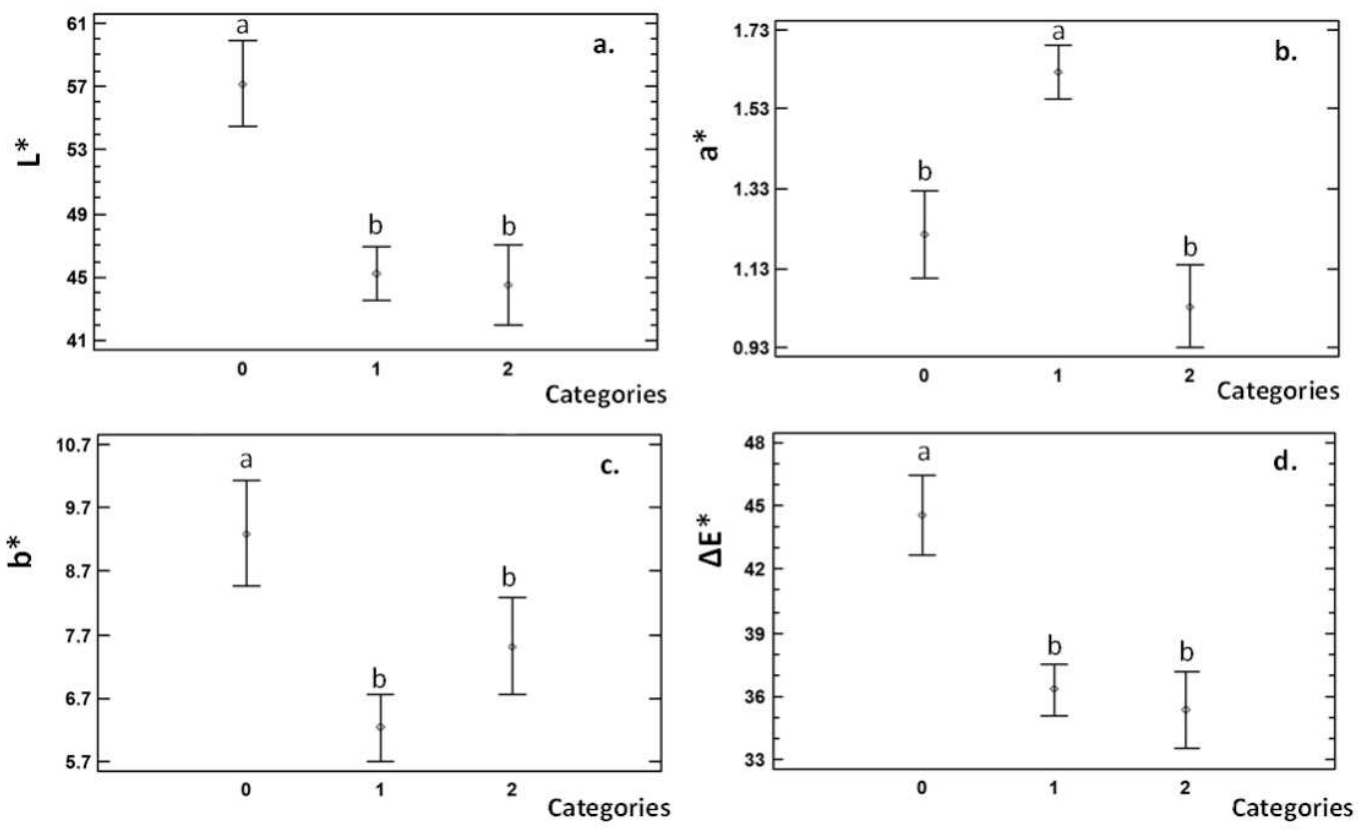

Figure 5.

This article is protected by copyright. All rights reserved 


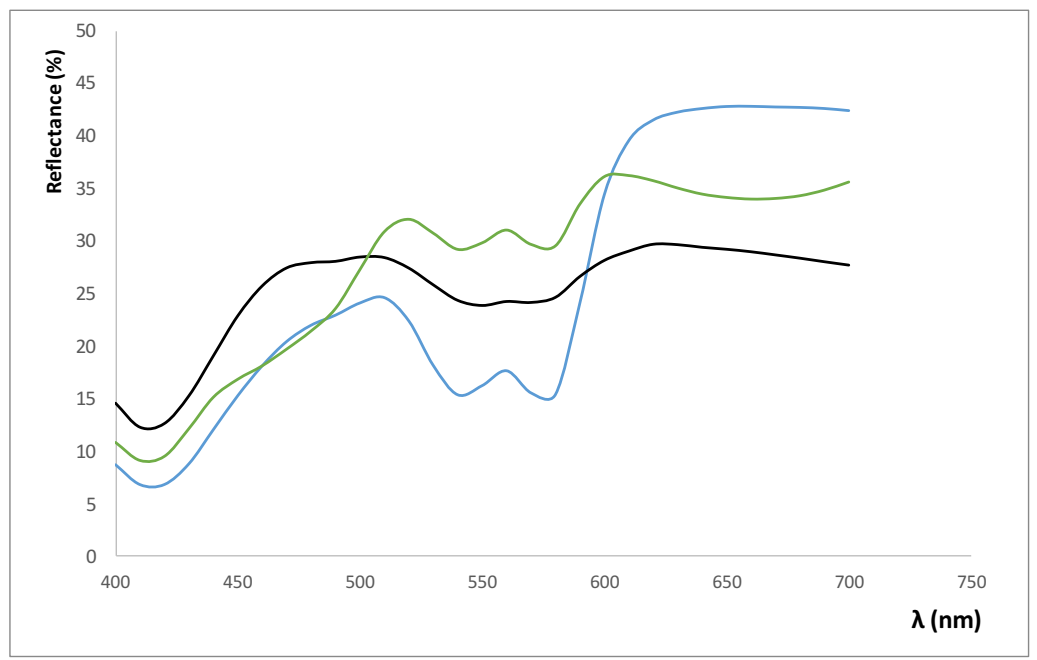

Figure 6.

This article is protected by copyright. All rights reserved 

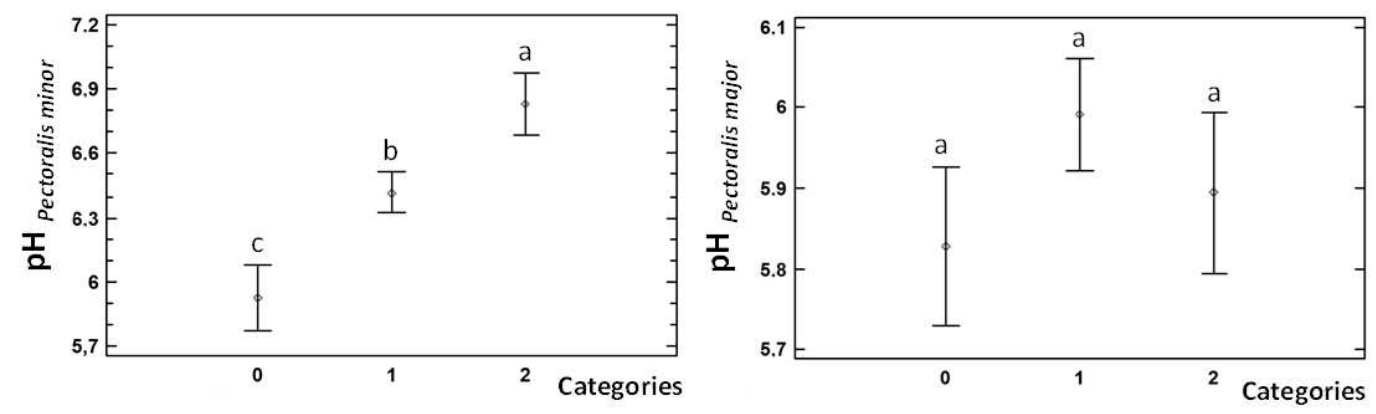

Figure 7. 


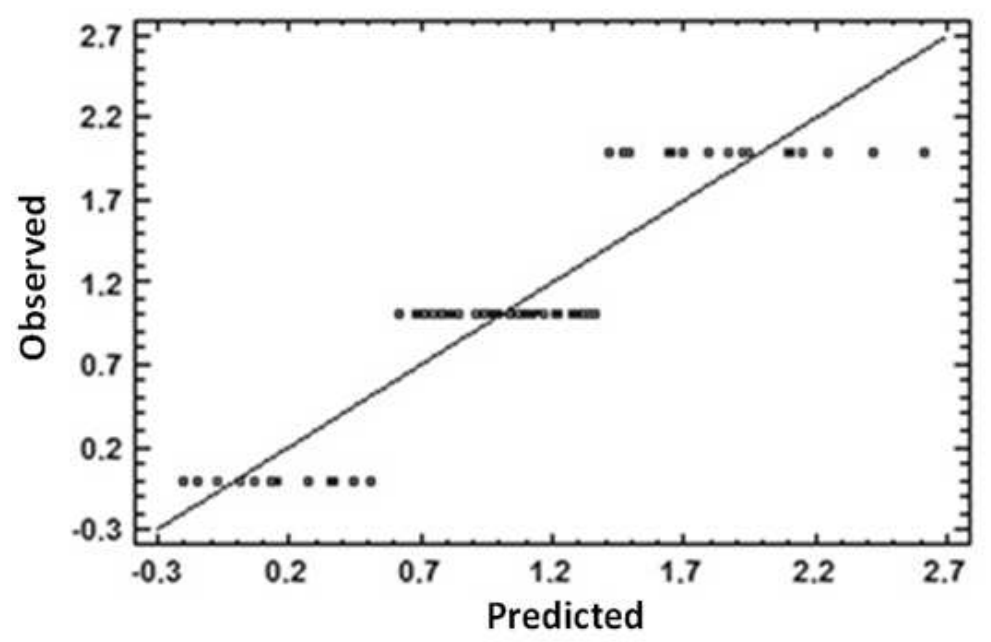

Figure 8.

This article is protected by copyright. All rights reserved 